\title{
Molecular characterisation of congenital myasthenic syndromes in Southern Brazil
}

\author{
V Mihaylova, ${ }^{1}$ R H Scola, ${ }^{2}$ B Gervini, ${ }^{2}$ P J Lorenzoni, ${ }^{2}$ C K Kay, ${ }^{2}$ L C Werneck, ${ }^{2}$ \\ R Stucka, ${ }^{1}$ V Guergueltcheva, ${ }^{1} \mathrm{M}$ von der Hagen, ${ }^{3}$ A Huebner, ${ }^{4}$ A Abicht, ${ }^{1}$ \\ J S Müller, ${ }^{5}$ H Lochmüller $^{5}$
}

\begin{abstract}
- An additional figure is published online only. To view these files please visit the journal online (http://jnnp.bmj. com)

${ }^{1}$ Department of Neurology, Friedrich-Baur-Institute, Ludwig-Maximilians-University, Munich, Germany

${ }^{2}$ Neuromuscular/Neurology Division, Hospital de Clinicas, Universidade Federal do Parana, Curitiba, Brazil

${ }^{3}$ Department of Pediatric Neurology, Technical University Dresden, Germany

${ }^{4}$ Children's Hospital, Technical University Dresden, Germany ${ }^{5}$ Institute of Human Genetics, University of Newcastle upon Tyne, International Centre for Life, Newcastle upon Tyne, UK
\end{abstract}

\section{Correspondence to}

Hanns Lochmüller, Institute of Human Genetics, University of Newcastle upon Tyne,

International Centre for Life, Newcastle upon Tyne, NE1 3BZ; UK; hanns.lochmuller@ newcastle.ac.uk

V Mihaylova and R H Scola are contributed equally to the study.

Received 11 March 2009 Revised 25 May 2009 Accepted 31 May 2009 Published Online First 20 June 2010

\begin{abstract}
Objective To perform genetic testing of patients with congenital myasthenic syndromes (CMS) from the Southern Brazilian state of Parana.
\end{abstract}

Patients and methods Twenty-five CMS patients from 18 independent families were included in the study. Known CMS genes were sequenced and restriction digest for the mutation RAPSN p.N88K was performed in all patients.

Results We identified recessive mutations of CHRNE in ten families, mutations in DOK7 in three families and mutations in COLO, CHRNA1 and CHRNB1 in one family each. The mutation CHRNE c.70insG was found in six families. We have repeatedly identified this mutation in patients from Spain and Portugal and haplotype studies indicate that CHRNE c.70insG derives from a common ancestor.

Conclusions Recessive mutations in CHRNE are the major cause of CMS in Southern Brazil with a common mutation introduced by Hispanic settlers. The second most common cause is mutations in DOK7. The minimum prevalence of CMS in Parana is $0.18 / 100000$.

\section{INTRODUCTION}

Congenital myasthenic syndromes (CMS) are a heterogeneous group of inherited disorders characterised by impaired neuromuscular transmission. Genes known to cause CMS if mutated are the presynaptic choline acetyltransferase gene CHAT, the gene COLQ encoding the triple-stranded collagenic tail (ColO) of the synaptic acetylcholinesterase, the genes encoding the different subunits of the acetylcholine receptor (AChR) (CHRNA1, CHRNB1, CHRND, CHRNE), the genes for the postsynaptic proteins rapsyn (RAPSN), musclespecific kinase (MUSK) and MuSK-interacting cytoplasmic protein Dok-7 (DOK7). ${ }^{1}$ Recently, mutations in the gene encoding the laminin $\beta 2$ subunit $(L A M B 2)$ have been shown to cause severe CMS associated with congenital nephrosis and ocular malformations. ${ }^{2}$

Here we present the molecular genetic findings of 25 CMS Brazilian patients. We found two novel mutations in CHRNE and one novel mutation in DOK7. The most frequently detected mutation was CHRNE c.70insG which derives from a common ancestor.

\section{PATIENTS AND METHODS}

Twenty-five CMS patients from 18 independent families were included in the study. Pedigrees of five CMS families are shown in online figure 1. All patients were referred to a single center in Curitiba and examined by two independent investigators.

Detailed neurological examination and electrophysiological studies including $3-\mathrm{Hz}$ repetitive stimulation of proximal, distal and facial muscles were performed.

Venous blood samples were obtained from the patients as well as from their parents and siblings, if available. In all CMS families screening for the mutation RAPSN N88K was performed by restriction digest. 100 healthy controls were screened for each novel mutation.

Known CMS genes (CHRNE, DOK7, RAPSN, COLQ, CHRNA1, CHRNB1, CHRND) were sequenced depending on patients' clinical symptoms.

Haplotype studies using six polymorphic microsatellite markers on chromosome $17 \mathrm{p} 13.2$ (D17S1583, D17S1828, D17S1584, D17S1810, D17S1832, D17S796) were performed in a total of 38 patients and family members carrying CHRNE c.70insG and control individuals of Spanish or Portuguese origin.

All the studies were carried out with informed consent of the patients or parents and comply with the ethical guidelines of the institutions involved.

\section{RESULTS}

We found the molecular defect causing CMS in a total of 22 Brazilian patients. First we screened in all families for the common mutations RAPSN $\mathrm{p}$. N88K and DOK7 c.1124_1127dupTGCC. Subsequently, we sequenced $C \bar{H} R N E$ in patients with ophthalmoparesis and benefit from esterase inhibitors. Sequencing of the exons encoding the extracellular and transmembrane domains of AChR subunits was performed in patients with slowchannel CMS (SCCMS). Although the clinical phenotype of patients 24 and 25 is compatible with CMS, no mutations were found by sequencing CHRNE, CHRNA1, CHRNB1, CHRND and RAPSN. In patient 20 the common DOK7 mutation c.1124_1127dupTGCC was found heterozygously. A second DOK 7 mutation was not identified on genomic level. However, some DOK 7 mutations are identifiable on cDNA only. ${ }^{3}$ No cDNA of our patient was available for mutation analysis.

All patients presented with myasthenic symptoms at birth or in childhood. The individual clinical data is summarised in table 1. Representative photos of patients are shown in figure 1.

Molecular genetic analysis revealed recessive mutations in CHRNE in a total of 16 patients out 


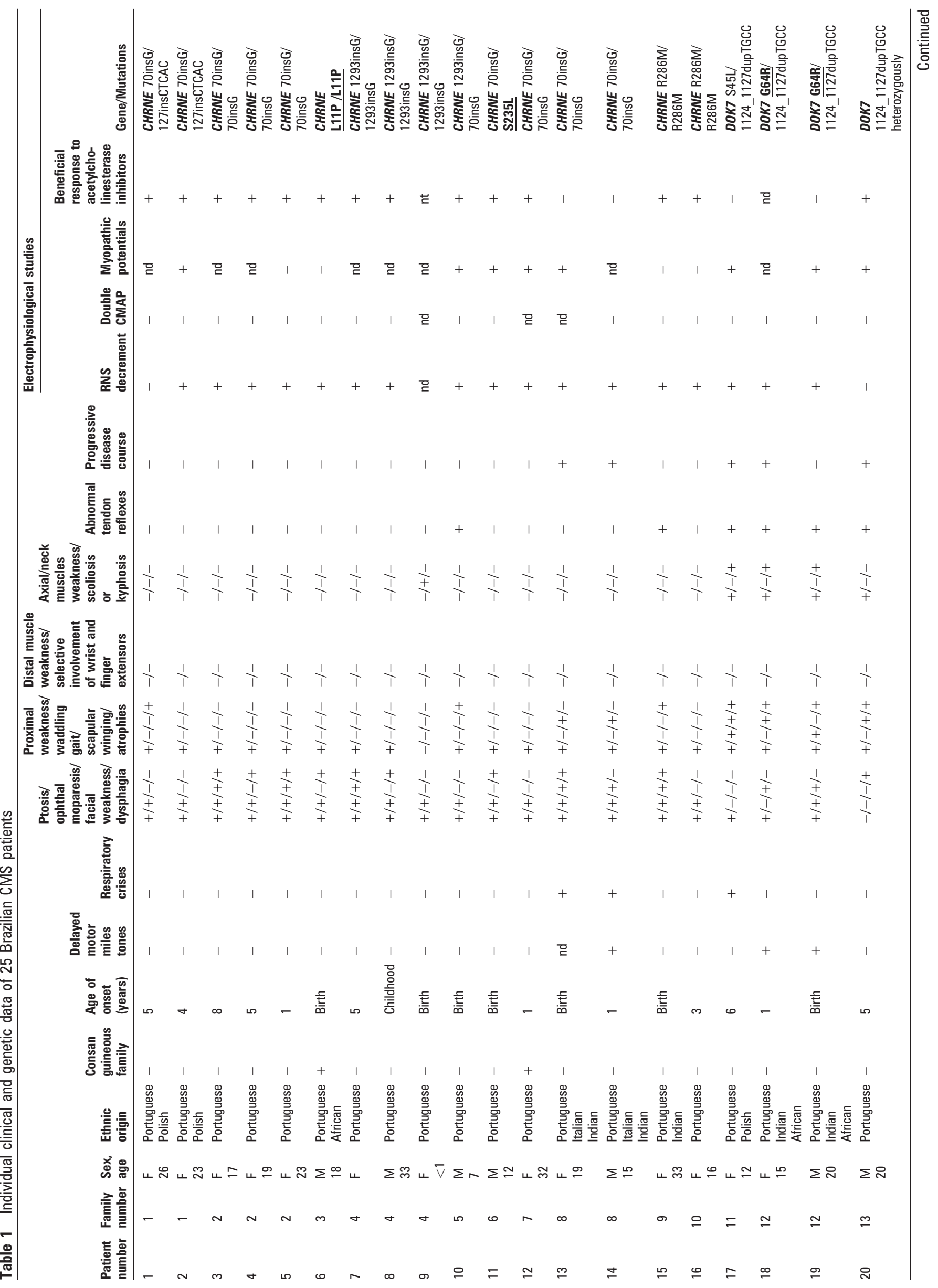




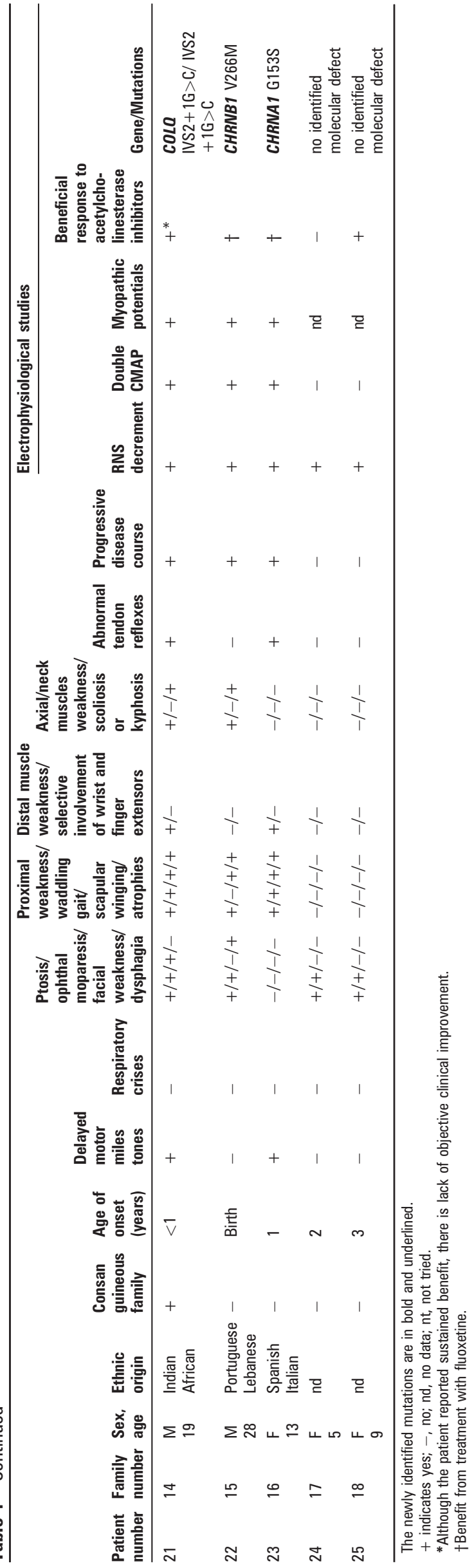

of ten families, two of them are novel (table 1). The newly identified mutation CHRNE p.L11P was detected homozygously in patient 6 and leads to a substitution of a highly conserved leucine. The mutation CHRNE p.S235L found in patient 11 has not been previously reported, but was detected homozygously in an Austrian CMS patient by us (unpublished data) and leads to a substitution of a highly conserved serine. Interestingly, the previously published mutation $C H R N E$ c.70ins $G^{4}$ was found on at least one allele in ten patients from six families. All of these patients are of Portuguese or mixed Portuguese, European and Indian origin (table 1).

Other previously published CHRNE mutations detected in our patients are: CHRNE c.1293insG ${ }^{5}$ found in four patients from two families and CHRNE p.R286 ${ }^{6}$ detected homozygously in two patients from two kinships.

Thus, mutations in CHRNE accounted for approximately $70 \%$ of our Brazilian CMS patients with identified molecular defect. The second most common molecular cause in this cohort is DOK7 mutations, found in four patients (17\%) from three kinships (table 1). All of them carry the common mutation DOK7 c.1124_1127dupTGCC heterozygously.

Two siblings are compound heterozygotes for a newly identified aminoacid exchange DOK7 p.G64R leading to a substitution of a highly conserved glycine.

Patient 17 carries the previously reported mutation $D O K 7$ p.S45L together with the mutation DOK7 c.1124_1127dupTGCC.

Patient 21 (previously reported ${ }^{8}$ ) has a homozygous splice-site mutation in COLQ.

Patients 22 and 23 with SCCMS carry previously reported mutations heterozygously: CHRNB1 p.V266 $\mathrm{M}^{9}$ and CHRNA1 p.G153S, ${ }^{10}$ respectively.

We and others have repeatedly identified patients from Spain and Portugal harbouring the mutation CHRNE c.70insG. ${ }^{11}$

Haplotype studies of patients and family members carrying CHRNE c.70insG showed that the distally adjacent polymorphic microsatellite marker D17S1810 had a fragment length of $260 \mathrm{bp}$ in 14 out of 1870 ins $G$ alleles (77.8\%). In contrast, the same fragment length (260bp) of D17S1810 was detected in 4 from 44 control alleles of Spanish or Portuguese descent only (9.1\%). The difference between controls and c.70insG carriers for marker $D 1751810$ is statistically significant $(\mathrm{p}<0.01)$ providing genetic evidence that the CHRNE c.70insG allele derives from a common ancestor. We estimate that a single founder event for the mutation CHRNE c.70insG may have occurred prior to the immigration of Europeans to South America.

\section{DISCUSSION}

Here we present the molecular genetic findings of 25 Brazilian CMS patients from the Southern Brazilian state of Parana.

Brazilians represent one of the most heterogeneous populations in the world reflecting the admixture of Europeans, Amerindians, Africans and Asians with regional differences of European, Amerindian and African matrilineal genetic contribution to the Brazilian mtDNA pool. ${ }^{12}$

We found that CHRNE mutations are the most common cause of CMS in Southern Brazil with CHRNE c.70insG mutation being the most frequently detected. Haplotype analysis of CHRNE c.70insG families suggests that this is an old founder mutation and the founder allele is shared by patients from Spain and Portugal. Similarly, CHRNE p.R286M has been previously identified in four patients from two Portuguese families from our CMS cohort (unpublished observation) and CHRNE c.1293insG 

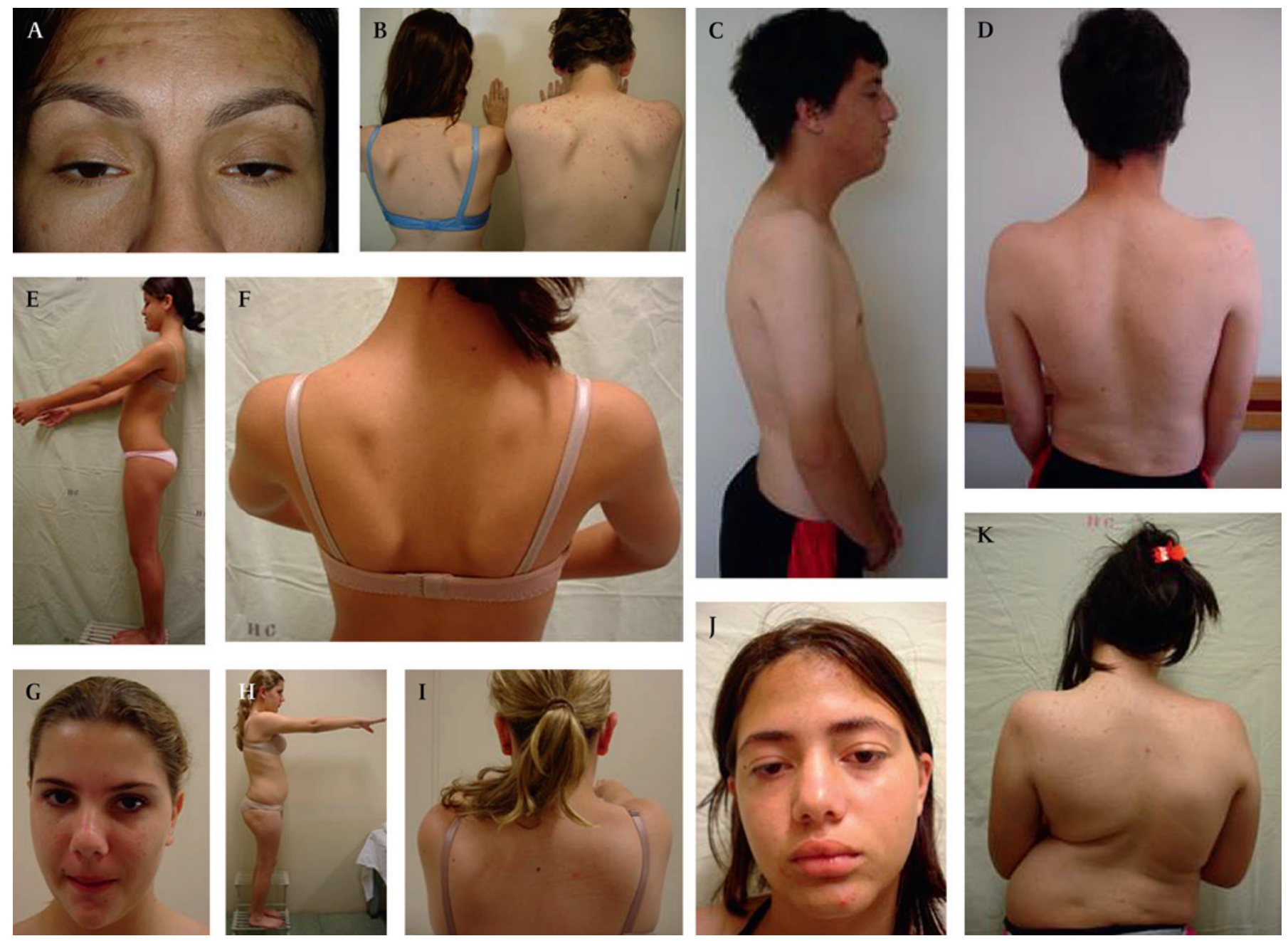

Figure 1 Photos of CMS patients A. Patient 12. The patient has ptosis and ophthalmoparesis. B. Patients 13 and 14 show scapulae alatae. C, D. Patient 19. Note pronounced lordosis and scoliosis. E, F. Patient 17. Note proximal weakness, pronounced lordosis and scapulae alatae. G, H, I. Patient 23. She has no involvement of the ocular muscles. Note pronounced lordosis and scapulae alatae. J, K. Patient 18. She has ptosis and facial weakness. Note severe scoliosis.

mutation has been reported causing CMS in patients of NorthAfrican, Portuguese and Spanish origin. ${ }^{11}$

CHRNE mutations are the most common cause of CMS in patients from Portugal analysed in our laboratory (a total of 11 Portuguese patients with identified molecular defect) accounting for $72.7 \%$ of the patients, that is, nearly the same frequency that we observed in our Brazilian cohort. The second most common cause is DOK 7 mutations. In contrast, approximately half of our German CMS patients (a total of 42 German patients with identified molecular defect) have mutations in RAPSN while mutations in CHRNE are found in $17 \%$ of the patients (unpublished results).

Taken together these findings indicate a strong influence of the Portuguese ancestry on the people from Parana which is in line with the data from mtDNA studies showing major European matrilineal genetic contribution to the mtDNA pool in Southern Brazil. ${ }^{12}$

The second molecular cause of CMS in Parana according to frequency is DOK 7 mutations. We found the common mutation DOK7 c.1124_1127dupTGCC in four patients. The mutation DOK7 p.S45L has previously been identified by us in one Portuguese patient and another patient from South America. ${ }^{7}$ The novel mutation DOK 7 p.G64R has not previously been observed in any European CMS patient. The two siblings who carry it derive from a non-consanguineous family of mixed Portuguese, Amerindian and African descent. It can be speculated that DOK7 p.G64R is specific for the indigenous Amerindians or Africans, so testing of CMS patients from Northern and Northeastern Brazil is of particular interest as the Amerindian and African matrilineal genetic contribution to the mtDNA pool in these regions is greater than in the Southern Brazil. ${ }^{12}$

We did not detect the common European RAPSN p.N88K mutation $^{1}$ in the Brazilian CMS cohort. The likely reason for this is underdiagnosis of CMS among hospitalised neonates at Intensive Care Units and the benign course of the disease in RAPSN patients with lack of progression with age. Alternatively, this mutation could be very rare in Brazil, similarly to patients from Portugal (RAPSN N88K was detected heterozygously in one patient out of 11 of our CMS Portuguese patients).

The Southern Brazilian state of Parana has a total population of 10 million inhabitants. Eighteen independent CMS families included in the study were referred to a single neuromuscular center in Curitiba. Based on these figures, the estimated minimum prevalence of CMS in Parana is approximately 0.18 in 100 000, which does not differ from figures published for Europe prior to the identification of $D O K 7$ mutations. ${ }^{13}$ The prevalence 
may be underestimated assuming that there are underdiagnosed patients that have not been referred to Curitiba.

With our findings we show that molecular epidemiology of CMS in Parana - similar to other disorders (eg, spinocerebellar ataxia) - reflects the major Portuguese ancestry of the Brazilian population. Recessive mutations in CHRNE are the most common cause of CMS in Southern Brazil with a common founder mutation introduced by Hispanic settlers. In practical terms, we recommend to start genetic testing for CMS in Brazil with screening for mutations in CHRNE followed by DOK7.

Acknowledgements We wish to thank the patients and their families for participating in this study. We thank Mandy Heiliger and Petra Mitzscherling for excellent technical assistance. $\mathrm{AA}, \mathrm{AH}, \mathrm{MvH}, \mathrm{RS}$ and $\mathrm{HL}$ are members of the German Muscular Dystrophy Network (MD-NET 01GM0601) funded by the German Ministry of Education and Research (BMBF, Bonn, Germany); http://www.md-net. org. MD-NET is a partner of TREAT-NMD (EC, $6^{\text {th }} \mathrm{FP}$, proposal \#036825; http:// www.treat-nmd.eu). VM receives a BAYHOST fellowship from the Bavarian state. JSM receives a fellowship from the Deutsche Forschungsgemeinschaft (MU2840/ 1-1). VG is a research fellow of the Alexander von Humboldt Foundation.

Competing interests None.

Patient consent Obtained.

Provenance and peer review Not commissioned; externally peer reviewed.

\section{REFERENCES}

1. Müller JS, Mihaylova V, Abicht A, et al. Congenital myasthenic syndromes: spotlight on genetic defects of neuromuscular transmission. Expert Rev Mol Med 2007:9:1-20.

2. Maselli RA, $\mathrm{Ng} \mathrm{JJ}$, Anderson JA, et al. Mutations in LAMB2 causing a severe form of synaptic congenital myasthenic syndrome. J Med Genet 2009;46:203-8.

3. Selcen D, Milone M, Shen XM, et al. Dok-7 myasthenia: phenotypic and molecular genetic studies in 16 patients. Ann Neurol 2008;64:71-87.

4. Ohno K, Anlar B, Özdirim E, et al. Myasthenic syndromes in Turkish kinships due to mutations in the acetylcholine receptor. Ann Neurol 1998;44:234-41.

5. Engel AG, Ohno K, Bouzat C, et al. End-plate acetylcholine receptor deficiency due to nonsense mutations in the $\epsilon$ subunit. Ann Neurol 1996:40:810-17.

6. Ohno K, Tsujino A, Shen XM, et al. Spectrum of splicing errors caused by CHRNE mutations affecting introns and intron/exon boundaries. J Med Genet 2005;42:e53.

7. Müller JS, Herczegfalvi A, Vilchez JJ, et al. Phenotypical spectrum of DOK7 mutations in congenital myasthenic syndromes. Brain 2007;130:1497-506.

8. Mihaylova V, Müller JS, Vilchez JJ, et al. Clinical and molecular genetic findings in COLQ-mutant congenital myasthenic syndromes. Brain 2008:131:747-59.

9. Engel AG, Ohno K, Milone M, et al. New mutations in acetylcholine receptor subunit genes reveal heterogeneity in the slow-channel congenital myasthenic syndromes. Hum Mol Genet 1996;5:1217-27.

10. Sine SM, Ohno K, Bouzat C, et al. Mutation of the acetylcholine receptor $\alpha$ subunit causes a slow-channel myasthenic syndrome by enhancing agonist binding affinity. Neuron 1995;15:229-39.

11. Beeson D, Hantai D, Lochmüller $\mathrm{H}$, et al. 126th International Workshop: congenital myasthenic syndromes, 24-26 September 2004, Naarden, The Netherlands. Neuromuscul Disord 2005;15:498-512.

12. Alves-Silva J, Santos M, Guimaraes $P$, et al. The ancestry of Brazilian mtDNA lineages. Am J Hum Genet 2000;67:444-61.

13. Hantai D, Richard P, Koenig J, et al. Congenital myasthenic syndromes. Curr Opin Neurol 2004:17:539-51. 


\title{
JNNP
}

\section{Molecular characterisation of congenital myasthenic syndromes in Southern Brazil}

\author{
V Mihaylova, R H Scola, B Gervini, et al.
}

J Neurol Neurosurg Psychiatry 2010 81: 973-977 originally published online June 20, 2010

doi: 10.1136/jnnp.2009.177816

Updated information and services can be found at:

http://jnnp.bmj.com/content/81/9/973.full.html

These include:

References This article cites 13 articles, 5 of which can be accessed free at: http://jnnp.bmj.com/content/81/9/973.full.html\#ref-list-1

Article cited in:

http://jnnp.bmj.com/content/81/9/973.full.html\#related-urls $\begin{gathered}\text { Email alerting } \\ \text { service }\end{gathered}$
Receive free email alerts when new articles cite this article. Sign up in
the box top right corner of the online article.

Topic Articles on similar topics can be found in the following collections Collections

Neuromuscular disease (1122 articles)

Notes

To request permissions go to:

http://group.bmj.com/group/rights-licensing/permissions

To order reprints go to:

http://journals.bmj.com/cgi/reprintform

To subscribe to BMJ go to:

http://group.bmj.com/subscribe/ 